\title{
Pharmacokinetics of Marbofloxacin after Single Intravenous Administration in Calves
}

\author{
Neelam Dinodia, Pratishtha Sharma*, Ashok Gaur and Mamta Meena \\ Department of Veterinary Pharmacology and Toxicology, College of Veterinary and Animal \\ Science, RAJUVAS, Bikaner - 334001 (Rajasthan, India) \\ *Corresponding author
}

\section{A B S T R A C T}

\section{Keywords}

Calves,

marbofloxacin, pharmacokinetics

Article Info

Accepted:

12 May 2019

Available Online:

10 June 2019
Marbofloxacin is a third generation quinolone developed exclusively for veterinary use. The disposition kinetic profile of marbofloxacin was generated after a single intravenous bolus injection in male Sahiwal calves $(\mathrm{n}=5)$ at the dose level of $2 \mathrm{mg} \cdot \mathrm{kg}^{-1}$ body weight. Marbofloxacin concentrations in plasma were determined by microbiological assay using Escherichia coli MTCC 443 as the test organism. The plasma concentration-time profile following intravenous administration was best described by a two-compartment open model. The plasma drug concentration $\geq 0.12 \mu \mathrm{g} \cdot \mathrm{ml}^{-1}$ was detected at $24 \mathrm{~h}$. The distribution $\left(\mathrm{t}_{1 / 2 \alpha}\right)$ and elimination $\left(\mathrm{t}_{1 / 2 \beta}\right)$ half-lives were $0.12 \pm 0.01 \mathrm{~h}$ and $5.73 \pm 0.15 \mathrm{~h}$, respectively. Area under plasma drug concentration-time curve (AUC), mean residence time $(\mathrm{MRT})$, apparent volume of distribution $\left(\mathrm{Vd}_{\text {area }}\right)$ and total body clearance $\left(\mathrm{Cl}_{\mathrm{B}}\right)$ were $16.49 \pm 0.58 \mu \mathrm{g} \cdot \mathrm{ml}^{-1} \cdot \mathrm{h}, 8.00 \pm 0.19 \mathrm{~h}, 1.01 \pm 0.03 \mathrm{~L} \cdot \mathrm{kg}^{-1}$ and $0.12 \pm 0.00 \mathrm{~L}^{\mathrm{kg}} \mathrm{kg}^{-1} \mathrm{~h}^{-1}$, respectively. Marbofloxacin at the dose rate of $2 \mathrm{mg} \cdot \mathrm{kg}^{-1}$ body weight once daily by intravenous route is sufficient in calves for treatment of susceptible bacterial infections.

\section{Introduction}

Marbofloxacin is a fluoroquinolone systemic antimicrobial agent specifically developed for veterinary use (Garcia-Montijano et al., 2006; Ismail and El-Kattan, 2007; PalloZimmerman et al., 2010; Sidhu et al., 2010a; Pillet et al., 2013 and Cao et al., 2015).

Marbofloxacin has a larger volume of distribution, longer elimination half-life, virtually complete bioavailability after parenteral administration (Altan et al., 2018) and longer post antibiotic effect (Carbone et al., 2001). It, being a fluoroquinolone, shows concentration-dependent bactericidal activity (Pellet et al., 2006 and Celani et al., 2017). It distributes extensively to most tissues including the lung, at higher concentrations than in serum/plasma (Dorey et al., 2017).

\section{Materials and Methods}

\section{Drug}

For intravenous administration, marbofloxacin injection of a reputed multinational commercial brand was 
purchased from local market. One $\mathrm{ml}$ of the injection contains $100 \mathrm{mg}$ marbofloxacin.

\section{Animals for experiment}

The pharmacokinetic study was done on five clinically healthy male Sahiwal calves (A to E) maintained at livestock research station (LRS Kodamdesar) of Rajasthan University of Veterinary and Animal Sciences, Bikaner (India). The calves were regularly dewormed, aging 4-6 months and weighing between 40$60 \mathrm{~kg}$. The study was done after communication of approval from the Institutional Animal Ethics committee of Rajasthan University of Veterinary and Animal Sciences, Bikaner. The animals were kept and maintained in the farm under standard management conditions, were given standard ration and had free access to roughage and water.

\section{Experimental design}

Marbofloxacin injection at the dose rate of 2.0 mg. $\mathrm{kg}^{-1}$ body weight was administered in the jugular vein and blood samples were collected in test tubes containing anticoagulant, immediately before administration of marbofloxacin $(0 \mathrm{~h})$ and at 0.04, 0.08, 0.17, $0.25,0.50,0.75,1.0,1.5,2.0,4.0,6.0,8.0,10$, $12,24,36$ and $48 \mathrm{~h}$ after administration of the drug. Plasma samples were harvested from the blood samples centrifuged at $3000 \mathrm{rpm}$ for 15 min. Plasma samples were stored at $-20^{\circ} \mathrm{C}$ until analysis.

\section{Drug assay}

Concentration of marbofloxacin in plasma samples was determined by microbiological assay method (Arret et al., 1971) using Escherichia coli MTCC 443 (ATCC 25922) as test organism (Haritova et al., 2006; Tohamy and El-Gendy, 2013 and Aboubakr and Abdelazem, 2015). Six equidistant wells of $6 \mathrm{~mm}$ diameter were made in standard petri-dishes containing $25 \mathrm{ml}$ of seeded agar. The wells were filled with 100 microlitres of either the test samples or marbofloxacin standard concentrations. The plates were incubated at $37^{\circ} \mathrm{C}$ for $24 \mathrm{~h}$. The inhibition zone diameters were measured and the marbofloxacin concentrations in the test samples were extrapolated from the standard curve. The lowest detection limit of the assay was $0.1 \mu \mathrm{g} \cdot \mathrm{ml}^{-1}$. Standard curve were prepared using antibacterial-free pooled plasma collected from the animals prior to the experiment. Standard marbofloxacin solutions having its concentrations of $0.098,0.195$, $0.391,0.78,1.56,3.125,6.25,12.5$ and 25 $\mu \mathrm{g} . \mathrm{ml}^{-1}$ were prepared in vitro. Semilogarithmic plot of the zones of inhibition versus standard drug concentrations gave a linear plot having correlation coefficient of 0.980 .

\section{Pharmacokinetic analysis}

The plasma marbofloxacin concentration time profile of each animal following intravenous injection of marbofloxacin was used to determine the pharmacokinetic variables describing the distribution and elimination characteristics of marbofloxacin in calves. To determine the different disposition kinetic variables, plasma drug concentration-time data were analyzed by employing the compartmental pharmacokinetic models (Baggot, 2001; Gibaldi and Perrier, 2007).

The plasma concentration versus time data following a single bolus dose of marbofloxacin were best fitted to a twocompartment open model using the biexponential equation:

$\mathrm{Cp}=A \mathrm{e}^{-\alpha \mathrm{t}}+\mathrm{Be}^{-\beta \mathrm{t}},($ Riviere, 2016)

Where ' $\mathrm{Cp}$ ' is the plasma concentration at time ' $t$ '; ' $\alpha$ ' and ' $\beta$ ' are the distribution and 
the elimination rate constants; 'A' and B are the zero time intercepts of distribution and elimination phases, respectively; and ' $\mathrm{e}$ ' is the base of natural logarithm.

The pharmacokinetic analysis providing the above rate constants, so derived by linear regression and method of residuals, were used to calculate the respective half-life values. Other pharmacokinetic parameters were computed according to the standard formulae (Baggot, 2001; Gibaldi and Perrier, 2007). Values of all the pharmacokinetic parameters have been expressed as the mean $\pm \operatorname{SE}(n=5)$.

\section{Results and Discussion}

Plasma marbofloxacin concentration versus time data is plotted on a semi logarithmic graph shown in Figure 1. Following intravenous administration of marbofloxacin, the drug concentration of $4.70 \pm 0.07 \mu \mathrm{g} \cdot \mathrm{ml}^{-1}$ was observed at $0.04 \mathrm{~h}$ which rapidly declined to $2.65 \pm 0.06 \mu \mathrm{g} \cdot \mathrm{ml}^{-1}$ at $0.25 \mathrm{~h}$ and then gradually decreased to $0.12 \pm 0.00 \mu \mathrm{g} \cdot \mathrm{ml}^{-1}$ at $24 \mathrm{~h}$. Concentrations above the minimum inhibitory concentration (MIC) level of $\geq 0.10$ $\mu \mathrm{g} \cdot \mathrm{ml}^{-1}$ were maintained up to $24 \mathrm{~h}$.

The plasma concentration versus time profile following single intravenous dose of marbofloxacin was best described by a two compartment open model which is similar to that described in dogs (Bidgood and Papich, 2005), cats (Albarellos et al., 2005), healthy and Mannheimia haemolytica infected calves (Ismail and El-Kattan, 2007), sheep (Sidhu et al., 2010b), llamas (Rubio-Langre et al., 2012), foals (Tohamy and El-Gendy, 2013), Japanese quails (Aboubakr and Abdelazem, 2015) and lactating buffaloes (Elzoghby and Aboubakr, 2015).

Different disposition kinetic parameters have been summarized in Table 1. The distribution half-life $\left(\mathrm{t}_{1 / 2 \alpha}\right)$ was found to be $0.12 \pm 0.01 \mathrm{~h}$ which is suggestive of its rapid distribution into different body tissues and fluids of calves. Comparable value of $t_{1 / 2 \alpha}(0.13 \pm 0.02$ $\mathrm{h}$ ) is found in calves by Ismail and El-Kattan (2007) and similar value in dogs $(0.12 \pm 0.04$ h) has been reported by Bidgood and Papich (2005) at the same dose rate.

The concentration dependent bactericidal effect together with short distribution half-life of marbofloxacin suggest it as useful in acute systemic infections where the therapeutic concentrations of antimicrobial agent are required to be achieved within very short period.

The elimination half-life $\left(t_{1 / 2 \beta}\right)$ was found to be $5.73 \pm 0.15 \mathrm{~h}$ in the present study. It reflects the advantage of this drug in maintaining effective concentration in the body thereby allowing longer time for drug-pathogen interaction. This finding is comparable to almost similar observation of $5.26 \mathrm{~h}$ in broiler chicken (Anadon et al., 2002). Longer elimination half-life $\left(t_{1 / 2 \beta}\right)$ values of marbofloxacin have been observed in cats (Albarellos et al., 2005), dogs (Bidgood and Papich, 2005), turkeys (Haritova et al., 2006), donkeys (Gonzalez et al., 2007), vultures (Garcia-Montijano et al., 2011), llamas (Rubio-Langre et al., 2012), foals (Tohamy and El-Gendy, 2013) and chicken (Pizarro et al., 2017) with the corresponding values of $7.98 \pm 0.57 \mathrm{~h}, 8.30 \pm 2.61 \mathrm{~h}, 9.01 \pm 3.14 \mathrm{~h}$, $8.88 \pm 2.20 \mathrm{~h}, 12.51 \pm 2.52 \mathrm{~h}, 8.26 \pm 1.55 \mathrm{~h}$, $6.40 \pm 0.08 \mathrm{~h}$ and $6.50 \pm 0.40 \mathrm{~h}$, respectively.

The average value of AUC was $16.49 \pm 0.58$ $\mu \mathrm{g} \cdot \mathrm{ml}^{-1} \cdot \mathrm{h}$, which is comparable to $16.30 \pm$ $1.80 \mu \mathrm{g} \cdot \mathrm{ml}^{-1} . \mathrm{h}$ in donkeys (Gonzalez et al., 2007). Lower AUC values of marbofloxacin have been observed in dogs (Bidgood and Papich, 2005), turkeys (Haritova et al., 2006), buffalo calves (Baroni et al., 2007), calves (Ismail and El-kattan, 2007), cattle (Belew et al., 2015) and lactating buffaloes (Elzoghby 
and Aboubakr, 2015) with the corresponding values of $6.53 \pm 1.11 \mu \mathrm{g} . \mathrm{ml}^{-1}$.h, $13.41 \pm 2.64$ $\mu \mathrm{g} . \mathrm{ml}^{-1}$.h, $8.42 \pm 3.71 \mu \mathrm{g} . \mathrm{ml}^{-1}$.h, $11.70 \pm 1.34$ $\mu \mathrm{g} . \mathrm{ml}^{-1} . \mathrm{h}, 6.87 \pm 0.52 \mu \mathrm{g} \cdot \mathrm{ml}^{-1} \cdot \mathrm{h}$ and $10.51 \pm$ $0.44 \mu \mathrm{g} \cdot \mathrm{ml}^{-1} \cdot \mathrm{h}$, respectively when given at the same dose rate of $2 \mathrm{mg} \cdot \mathrm{kg}^{-1}$ body weight.

Fig.1

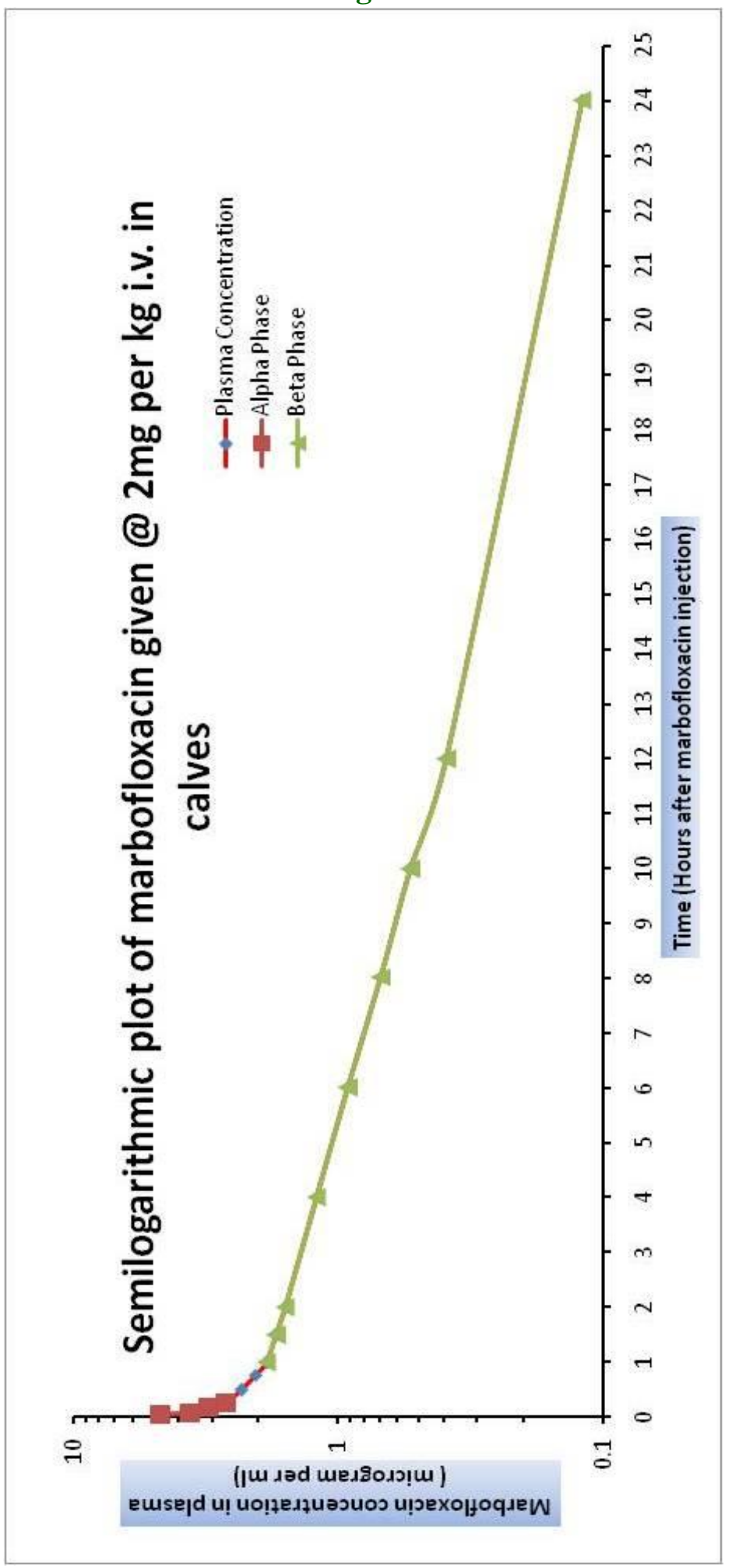


Table.1 Pharmacokinetic determinants of marbofloxacin in calves following a single intravenous dose of 2 mg.kg-1 body weight employing compartmental model

\begin{tabular}{|l|l|c|}
\hline \multicolumn{1}{|c|}{ Parameter } & \multicolumn{1}{c|}{ Unit } & Mean \pm S.E. \\
\hline $\mathbf{A}$ & $\mu \mathrm{g} \cdot \mathrm{ml}^{-1}$ & $3.11 \pm 0.14$ \\
\hline $\boldsymbol{\alpha}$ & $\mathrm{h}^{-1}$ & $5.76 \pm 0.50$ \\
\hline $\mathbf{t}_{1 / 2 \boldsymbol{\alpha}}$ & $\mathrm{h}$ & $0.12 \pm 0.01$ \\
\hline $\mathbf{B}$ & $\mu \mathrm{g} \cdot \mathrm{ml}^{-1}$ & $1.92 \pm 0.07$ \\
\hline $\boldsymbol{\beta}$ & $\mathrm{h}^{-1}$ & $0.12 \pm 0.00$ \\
\hline $\mathbf{t}_{1 / \mathbf{\beta}}$ & $\mathrm{h}$ & $5.73 \pm 0.15$ \\
\hline $\mathbf{C} \mathbf{p}^{\mathbf{0}}$ & $\mu \mathrm{g} \cdot \mathrm{ml}^{-1}$ & $5.04 \pm 0.13$ \\
\hline $\mathbf{A U C}$ & $\mu \mathrm{g} \cdot \mathrm{ml}^{-1} \cdot \mathrm{h}$ & $16.49 \pm 0.58$ \\
\hline $\mathbf{A U M C}$ & $\mu \mathrm{g} \cdot \mathrm{ml}-1 \cdot \mathrm{h}^{2}$ & $132.25 \pm 6.58$ \\
\hline $\mathbf{M R T}$ & $\mathrm{h}$ & $8.00 \pm 0.19$ \\
\hline Kel & $\mathrm{h}^{-1}$ & $0.30 \pm 0.01$ \\
\hline $\mathbf{K}_{\mathbf{1 2}} / \mathbf{K}_{\mathbf{2 1}}$ & $\mathrm{ratio}$ & $1.46 \pm 0.09$ \\
\hline $\mathbf{V}_{\mathbf{c}}$ & $\mathrm{L} \cdot \mathrm{kg}^{-1}$ & $0.39 \pm 0.01$ \\
\hline $\mathbf{V d}_{\text {area }}$ & $\mathrm{L} \cdot \mathrm{kg}^{-1}$ & $1.01 \pm 0.03$ \\
\hline $\mathbf{V d}_{\mathbf{B}}$ & $\mathrm{L} \cdot \mathrm{kg}^{-1}$ & $1.04 \pm 0.04$ \\
\hline $\mathbf{V d}_{\mathbf{s s}}$ & $\mathrm{L} \cdot \mathrm{kg}^{-1}$ & $0.97 \pm 0.03$ \\
\hline $\mathbf{C l}_{\mathbf{B}}$ & $\mathrm{L} \cdot \mathrm{kg}^{-1} \cdot \mathrm{h}^{-1}$ & $0.12 \pm 0.00$ \\
\hline fc & $\mathrm{ratio}$ & $0.39 \pm 0.01$ \\
\hline
\end{tabular}

The mean value of apparent volume of distribution $\left(\mathrm{Vd}_{\text {area }}\right)$ recorded in this study was more than one following intravenous injection in calves $\left(1.01 \pm 0.03 \mathrm{~L}_{\mathrm{kg}} \mathrm{kg}^{-1}\right)$, indicated wide distribution of marbofloxacin to extravascular tissues suggesting, that marbofloxacin can be employed in the treatment of different systemic infections including deep seated infections.

The value of $\mathrm{Vd}_{\text {area }}$ in the present study is comparable to $1.54 \pm 0.39 \mathrm{~L} . \mathrm{kg}^{-1}$ in dogs (Bidgood and Papich, 2005) and $1.75 \pm 0.25$ $\mathrm{L.kg}^{-1}$ in turkeys (Haritova et al., 2006). Higher values of $\mathrm{Vd}_{\text {area }}$ have been observed $2.83 \pm 0.75{\mathrm{~L} . \mathrm{kg}^{-1}}^{-1}$ in horses (Bousquet-Melou et al., 2002) and $3.70 \pm 0.30{\mathrm{~L} . \mathrm{kg}^{-1}}^{-1}$ in chicken (Pizzaro et al., 2017). Wide distribution and penetration of marbofloxacin in body tissues and fluids of calves is further supported by $\mathrm{K}_{12} / \mathrm{K}_{21}$ ratio $(1.46 \pm 0.09)$ and $\mathrm{T} / \mathrm{P}$ ratio $(1.53$ \pm 0.10 ) of more than 1 .
Clearance $\left(\mathrm{Cl}_{\mathrm{B}}\right)$ in the present study was found to be $0.12 \pm 0.00 \mathrm{~L}^{\mathrm{kg}} \mathrm{kg}^{-1} \mathrm{~h}^{-1}$. This finding is comparable to horses (Carretero et al., 2002), turkeys (Haritova et al., 2006), donkeys (Gonzalez et al., 2007) and vultures (Garcia-Montijano et al., 2011) with the corresponding values of $0.19 \pm 0.04 \mathrm{~L}_{\mathrm{kg}}{ }^{-1} \mathrm{~h}^{-1}$, $0.11 \pm 0.04$ L.kg ${ }^{-1} \mathrm{~h}^{-1}, 0.10 \pm 0.02 \mathrm{~L} . \mathrm{kg}^{-1} \mathrm{~h}^{-1}$

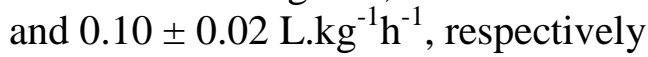

In conclusion, as marbofloxacin is a fluoroquinolone antimicrobial exerting concentration dependent killing of bacteria (Sidhu et al., 2011), the most appropriate $\mathrm{PK} / \mathrm{PD}$ parameters to describe drug efficacy is the Cmax: MIC ratio and AUC: MIC ratio (Craig, 2001). It is recommended that AUC: MIC ratio should be $\geq 125$ to optimize efficacy (Toutain et al., 2002) and Cmax: MIC (inhibitory ratio) should be $>10$ (McKeller et al., 2004). In the present study with single dose intravenous administration of 
marbofloxacin in calves at the dose rate of 2 mg. $\mathrm{kg}^{-1}$, the Cmax: MIC ratio was found 50.4 and similarly AUC: MIC ratio was found to 164.90, considering the MIC value to be 0.10 $\mu \mathrm{g} \cdot \mathrm{ml}^{-1}$. These values are well above the recommended values of $\mathrm{Cmax}$ : MIC ratio $\geq$ 10 and AUC:MIC ratio of $\geq 125$ thus suggest that marbofloxacin at the dose rate of 2 mg. $\mathrm{kg}^{-1}$ body weight and at $24 \mathrm{~h}$ dosing interval by intravenous is likely to be sufficient to treat bacterial infections requiring marbofloxacin concentration up to $0.10 \mu \mathrm{g} \cdot \mathrm{ml}^{-1}$.

\section{Acknowledgement}

The authors thankfully acknowledge the facilities, financial help and animal provided by the Principal Investigator of CEVPAM, Dean CVAS Bikaner and officer in-charge, LRS Kodamdesar, RAJUVAS, Bikaner.

\section{References}

Aboubakr, M. and Abdelazem, A. M. (2015). Pharmacokinetics of marbofloxacin in Japanese quails (Coturnix japonica) after different routes of administration. J Am Sci., 11(4): 136-142.

Albarellos, G. A., Montoya, L. and Landoni, M. F. (2005). Pharmacokinetics of marbofloxacin after single intravenous and repeat oral administration to cats. Vet. J., 170(2): 222-229.

Altan, F., Corum, O., Corum, D. D., Atik, O. and Uney, K. (2018). Pharmacokinetics and bioavailability of marbofloxacin in lambs following administration of intravenous, intramuscular and subcutaneous. Small Rumin. Res., 159: 5-10.

Anadon, A., Martinez-Larranaga, M. R., Diaz, M. J., Martinez, M. A., Frejo, M. T., Martinez, M., Tafur, M. and Castellano, J. (2002). Pharmacokinetic characteristics and tissue residues for marbofloxacin and its metabolite $\mathrm{N}$ desmethyl-marbofloxacin in broiler chickens. Am J Vet Res., 63: 927-933.

Arret, B., Johnoson, D.P. and Kirshaum, A. (1971). Outline of details of microbiological assay of antibiotics: second revision. J. Pharm. Sci., 60: 1489-1694.

Baggot, J. D. (2001). The Physiological Basis of Veterinary Clinical Pharmacology, Blackwell Science Ltd., UK. ISBN 0632-05744-0.

Baroni, E. E., Rodriguez, C., Crudeli, G., Perone, C., Rubio, S., de Lucas, J. J. and San Andres, M. I. (2007). Pharmacokinetics of marbofloxacin, after single intravenous administrations, in buffaloes calves. Ital. J. Anim. Sci., 6: 838-841. doi: 10.4081/ijas.2007.s2.838.

Belew, S., Kim, J. Y., Hossain, M. A., Park, J. Y., Lee, S. J., Park, Y. S., Suh, J. W., Kim, J. C. and Park, S. C. (2015). Pharmacokinetics of marbofloxacin after intravenous and intramuscular administration in Hanwoo, Korean native cattle. J. Vet. Med. Sci., 77(3): 327-329.

Bidgood, T. L. and Papich, M. G. (2005). Plasma and interstitial fluid pharmacokinetics of enrofloxacin, its metabolite ciprofloxacin, and marbofloxacin after oral administration and a constant rate intravenous infusion in dogs. J. Vet. Pharmacol. Ther., 28(4): 329-341.

Bousquet-Melou, A., Bernard, S., Schneider, M. and Toutain, P. L. (2002). Pharmacokinetics of marbofloxacin in horses. Equine Vet. J., 34(4): 366-372.

Cao, C., Qu, Y., Sun, M., Qiu, Z., Huang, X., Huai, B., Lu, Y. and Zeng, Z. (2015). In vivo antimicrobial activity of marbofloxacin against Pasteurella multocida in a tissue cage model in calves. Front. Microbiol, 6: 1-8. doi: 
10.3389/fmicb.2015.00759.

Carbone, M., Pennisi, M. G., Masucci, M., De Sarro, A., Giannone, M. and Fera, M. T. (2001). Activity and postantibiotic effect of marbofloxacin, enrofloxacin, difloxacin and ciprofloxacin against feline Bordetella bronchiseptica isolates. Vet. Microbiol, 81(1): 79-84.

Carretero, M., Rodriguez, C., San Andres, M. I., Fores, P., de Lucas, J. J., Nieto, J., Waxman, S., San Andres, M. D. and Gonzalez, F. (2002). Pharmacokinetic of marbofloxacin in adult horses after single intravenous and intramuscular administration. Equine Vet. J., 34: 360365.

Celani, G., Tulini, S. M. R., Montesano, C., Zezza, D., Sergi, M., Varasano, V., Mortellaro, C. M., Compagnone, D., Amorena, M. and Petrizzi, L. (2017). Pharmacokinetics of marbofloxacin administered via intravenous regional limb perfusion in dairy cows: evaluation of two different tourniquets. Vet Rec Open, 4: 1-7. doi: 10.1136/vetreco2017-000227.

Craig, W. A. (2001). Does the Dose Matter? Clinical Infectious Diseases, 33: 233237.

Dorey, L., Hobson, S. and Lees, P. (2017). Potency of marbofloxacin for pig pneumonia pathogens Actinobacillus pleuropneumonia and Pasteurella multocida: Comparison of growth media. Res. Vet. Sci., 111: 43-48.

Elzoghby, R. R and Aboubakr, M. (2015). Pharmacokinetics, Urinary Excretion and Milk Penetration of Marbofloxacin in Lactating Buffaloes. J Am Sci., 11(4): 23-28. http://www.jofamericanscience.org.

Garcia-Montijano, M., Waxman, S., de Lucas, J. J., Luaces, I., de San Andres, M. D. and Rodriguez, C. (2011). Disposition of marbofloxacin in vulture (Gyps fulvus) after intravenous administration of a single dose. Res. Vet. Sci., 90(2): 288-290.

Garcia-Montijano, M., Waxman, S., de Lucas, J. J., Luaces, I., Zalba, J., Gonzalez, F., San Andres, M. and Rodriguez, C. (2006). The pharmacokinetic behaviour of marbofloxacin in Eurasian buzzards (Buteu buteu) after intraosseous administration. Vet. J., 171(3): 551-555.

Gibaldi, M. and Perrier, D. (2007). Pharmacokinetics. 2nd edn., Marcel Deccar lnc., New York (USA).

Gonzalez, F., Rodriguez, C., De Lucas, J. J., Waxman, S., San Andres, M. D., Serres,C., Nieto, J. and San Andres, M. I. (2007). Pharmacokinetics of a single intravenous dose of marbofloxacin in adult donkeys. Vet. Rec., 161(4): 133136.

Haritova, A. M., Rusenova, N. V., Parvanov, P. R., Lashev, L. D. and FinkGremmels, J. (2006). Integration of Pharmacokinetic and Pharmacodynamic Indices of Marbofloxacin in Turkeys. Antimicrob. Agents Chemother, 50: 3779-3785.

ISBN 978-0-8138-2993-7

Ismail, M. and El-Kattan, Y. A. (2007). Comparative pharmacokinetics of marbofloxacin in healthy and Mannheimia haemolytica infected calves. Res. Vet. Sci., 82(3): 398-404.

Mckeller, Q. A., Sanchez Bruni, S. F. and Jones, D. G. (2004). Pharmacokinetic/ pharmacodynamic relationships of antimicrobial drugs used in veterinary medicine. J. Vet. Pharmacol. Ther, 27(6): 503-514.

Pallo-Zimmerman, L. M., Byron, J. k. and Graves, T. K. (2010). Fluoroquinolones: Then and Now. Copm. Cont. Edu. Vet, 32(7): E1-9.

Pellet, T., Gicquel-Bruneau, M., Sanders, P. and Laurentie, M. (2006). Comparison of faecal and optimal growth conditions on in vitro pharmacodynamic activity of 
marbofloxacin against Echerichia coli. Res. Vet. Sci., 80(3): 324-335.

Pillet, F., Montreuil, C., Roy, O., Grandemange, E. and Woehrle, F. (2013). Field experience with a single intravenous injection of marbofloxacin $16 \%$ in lactating dairy cows with acute clinical mastitis. Revue Med. Vet., 164: 537-545.

Pizarro, N. F. U., Errecalde, C. A., Prieto, G. F., Luders, C. F., Tonini, M. P. and Picco, E. J. (2017). Pharmacokinetic behavior of marbofloxacin in plasma from chickens at different seasons. Mac. Vet. Rev., 40(2): 143-147.

Riviere, J.E. (2011). Compartmental Models. In: Comparative Pharmacokinetics by Jim E. Riviere, $2^{\text {nd }}$ Edn., WileyBlackwell, 2121 State Avenue, Ames, Iowa 50014-8300, USA, pp. 142-186.

Rubio-Langre, S., De Lucas, J. J., Litterio, N. J., Aguilarb, S., Boggio, J. C. and San Andres, M. I. (2012). Pharmacokinetic behavior of marbofloxacin after intravenous, subcutaneous and intramuscular administrations in llamas (Lama glama). Small Rumin. Res., 106(1): 64-69.
Sidhu, P. K., Landoni, M. F., Aliabadi, F. S. and Lees, P. (2010b). PK-PD integration and modeling of marbofloxacin in sheep. Res. Vet. Sci., 88(1): 134-141.

Sidhu, P. K., Landoni, M. F., Aliabadi, F. S. and Lees, P. (2010a). Pharmacokinetic and pharmacodynamic modelling of marbofloxacin administered alone and in combination with tolfenamic acid in goats. Vet. J., 184(2): 219-229.

Sidhu, P. K., Landoni, M. F., Aliabadi, M. H., Toutain, P. L. and Lees, P. (2011). Pharmacokinetic and pharmacodynamic modelling of marbofloxacin administered alone and in combination with tolfenamic acid in calves. J. Vet. Pharmacol. Ther., 34(4): 376-387.

Tohamy, M. A. and El-Gendy, A. A. M. (2013). Some pharmacokinetic aspects and bioavailability of marbofloxacin in foals. Beni-suef Uni. J. Basic App. Sci., 2(1): 46-50.

Toutain, P. L., del Castillo, J. R. and Bousquet-Melou, A. (2002). The pharmacokinetic-pharmacodynamic approach to a rational dosage regimen for antibiotics. Res. Vet. Sci., 73(2): $105-114$.

\section{How to cite this article:}

Neelam Dinodia, Pratishtha Sharma, Ashok Gaur and Mamta Meena. 2019. Pharmacokinetics of Marbofloxacin after Single Intravenous Administration in Calves. Int.J.Curr.Microbiol.App.Sci. 8(06): 1521-1528. doi: https://doi.org/10.20546/ijcmas.2019.806.183 